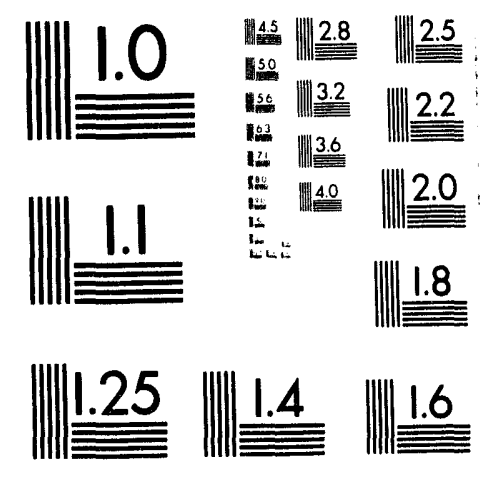



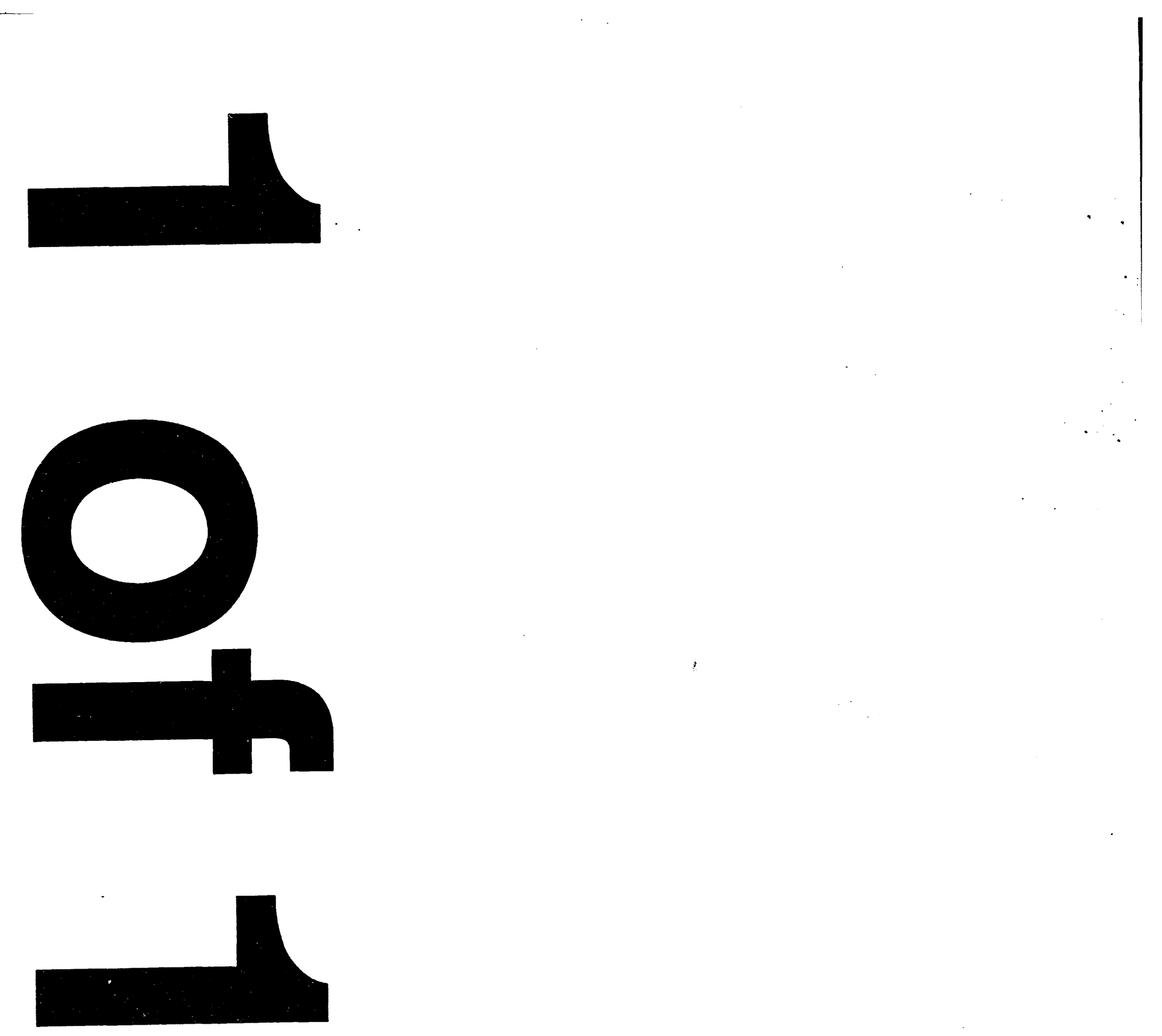


\title{
Quarterly Progress Report for Period Ending December 31, 1993
}

\section{HIGH TEMPERATURE MATERIALS TECHNOLOGY RESEARCH FOR ADVANCED THERMIONIC SYSTEMS}

\author{
Submitted to \\ U.S. Department of Energy \\ Office of Defense Energy Project
}

by

Ralph H. Zee

Materials Engineering Program

\author{
M. Frank Rose \\ Space Power Institute
}

Tel: (205) 844-3320

Fax: (205) 844-3400

\section{DISCLAIMER}

\begin{abstract}
This report was prepared as an account of work sponsored by an agency of the United States This report was prepared as an account of work sponsored by anency thereof, nor any of their employees, makes any warranty, express or implied, or assumes any legal liability or responsibility for the accuracy, completeness, or usefulness of any information, apparatus, product, or process disclosed, or represents that its use would not infringe privately owned rights. Referprocess herein to any specific commercial product, process, or service by trade name, trademark, manufacturer, or otherwise does not necessarily constitute or imply its endorsement, recommanufacturer, or otherwise does not necessarily constitute or imply its endors thereof. The views and opinions of authors expressed herein do not necessarily state or reflect those of the United States Government or any agency thereof.
\end{abstract}




\title{
HIGH TEMPERATURE MATERIALS TECHNOLOGY RESEARCH FOR ADVANCED THERMIONIC SYSTEMS
}

\author{
For the period $10 / 1 / 93$ to $12 / 31 / 93$
}

During the final quarter of the first year of this thermionic research program, effort has been concentrated on two aspects of the modeling of deformation in refractory alloy single crystals: deformation map in a tube with a [111] axial orientation and creep retardation due to solution strengthening. Both effects are important in the evaluation of single crystalline refractory alloys with a body-centered cubic structure for high temperature emitter applications.

Creep of molybdenum and tungsten single crystals has been reported by numerous authors ${ }^{1-5}$. It is known that the active slip systems are $\{110\}\langle 111\rangle$, $\{11 \overline{2}\}<111\rangle,\{1 \overline{3} 2\}<111>$ in these body-centered cubic metals. In simple tensile creep, the creep curve of single crystals is usually normalized by the maximum resolved shear stress on a selected active slip plane. However, the stress state experienced by the TFE cladding is more complex and resembles that of a thin wall cylinder subjected to an internal pressure. The wall of an internally pressured cylinder experiences a triaxial stress state with the circumferential stress (also called hoop stress or tangential stress) being the dominant one leading to an increase in the diameter of the cylinder at high temperatures. During the first three months of this project (January to March of 1993) a stress analysis based on a single crystal cylindrical tube under an internal pressure was conducted to determine the resolved shear stresses $(\tau)$ in various possible planes on the surface of a single crystal cylinder with a [110] growth direction. The distribution of the resolved stresses provides information on the deformation around the circumference of the cylinder. It was found that the macroscopic stress distribution was relatively isotropic although each slip system yielded discrete and anisotropic deformation. During the past three months (October to December), a similar analysis was made on a single crystalline tube with a [111] growth direction. This direction is important to thermionic applications because this orientation provides six (110) planes on the circumference (maximum number possible) and it is this (110) surface that gives the best thermionic emission characteristic. The resolve shear stress $(\tau)$ distributions for a [111] bcc single crystalline tube are shown in Figure 1. Three slip systems were considered, all of the $\{1 \overline{1} 0\}<111>$ type. The three slip systems result in identical deformation (shown by the solid, dashed and dotted lines), but rotated by $30^{\circ}$ as expected due to three-fold symmetry in the [111] direction. Consequently, the deformation due to a uniform hoop stress in cylindrical single crystal with a [111] axis will be quite uniform. A similar observation was made for a crystal with grown in a [110] direction. 
During the last quarter, significant progress has been made in the modeling of deformation in solution strengthened single crystals. The presence of solute atoms enhances the creep resistance of the naterial by dislocation pinning. Under the conditions of low applied stress and high temperature, this strengthening effect is due to the resistance of dislocation climb by solutes. The size misfit between the solute and the solvent atoms is the source of dislocation pinning. The model developed is based on the excess energy for dislocations to bow around solute atoms. Figure 2 illustrates such an interaction. The solute atoms are assumed to be evenly distributed. Climbing dislocations (due to applied stress) are pinned when they ericounter solute atoms due to the interaction of the strain field produced by the size misfit. The pinned dislocation line will bow upon increase in the applied stress. A balance in force will be established between the line tension of the dislocation $(T)$ and the resistance force of the solute (F). The bowing angle $(\phi)$ is a function of applied stress. The overall line length of the dislocation increases due to bowing. The force balance criterion yields:

$$
2 \mathrm{~T} \cos (\phi / 2)=\mathrm{F}
$$

The elastic interaction energy for a solute atom at a distance $r$ and an angle $\theta$ from a dislocation can be described as ${ }^{6}$

$$
\mathrm{U}(\mathrm{r}, \theta)=\mathrm{A}(\sin \theta) / \mathrm{r}
$$

where

$$
\mathrm{A}=(4 / 3)[(1+v) /(1-v)] \mathrm{GbeR}^{3}
$$

and $R$ is the atomic radius of the matrix, $G$ is the shear modulus of the material (temperature dependent), $\mathrm{b}$ is the Burger's vector $\left(2.7 \times 10^{-8} \mathrm{~cm}\right.$ for tungsten) and $v$ is the Poisson's ratio ( 0.28 for tungsten). The term $e$ is the strain misfit factor between the solute and the solvent (matrix) atoms. Table 1 gives the relevant atomic size parameters for three types of solutes ( $\mathrm{Re}, \mathrm{Nb}$ and $\mathrm{Hf}$ ) in tungsten?. The last column in Table 1 is the important misfit parameter $e$. This parameter is defined as the fractional difference in the atomic size difference of the solute of interest in a tungsten matrix. Absolute values of this parameter are given since the interaction between. dislocations and solute atoms only depends on the magnitude of this mismatch and not its sign. 
Table 1: Lattice Misfit Parameters between Tungsten and Three Solutes

\begin{tabular}{|c|c|c|c|}
\hline Element & $\begin{array}{c}\text { Atomic Radius } \\
\text { (R) } \\
\text { (in angstrom) }\end{array}$ & $\begin{array}{c}\text { Atomic Size } \\
\text { Difference } \\
\text { (relativc to W) }\end{array}$ & $\begin{array}{c}\text { Atomic Size } \\
\text { Mismatch } \\
\text { (e) }\end{array}$ \\
\hline $\mathrm{W}$ & 1.38 & 0.00 & 0.00 \\
\hline $\mathrm{Re}$ & 1.34 & -0.04 & 0.029 \\
\hline $\mathrm{Nb}$ & 1.44 & 0.06 & 0.042 \\
\hline $\mathrm{Hf}$ & 1.55 & 0.17 & 0.123 \\
\hline
\end{tabular}

When a dislocation approaches a solute atom through the climb process, the interaction energy (given in equation 2 ) increases. The maximum interaction occurs at a $\theta$ angle of $90^{\circ}$ (the dislocation approach the solute atom either from the top or bottom in Figure 2). Under this condition, the energy $U$ is simply $A / r$. The interaction force $F$ that the solute atom exerts on the dislocation to impede its climb is related to the derivative of the interaction energy $(F=-d U / d r)$. This interaction force between solute and dislocation increases as the applied stress increases. The maximum force $\left(\mathrm{F}_{\mathrm{c}}\right)$ that this interaction can provide prior to the breakaway of the dislocation from the solute atoms can be computed by first determining the interaction force through $\mathrm{F}=-\mathrm{dU} / \mathrm{dr}$ yielding:

$$
F=(4 / 3)(1+v) G b e R^{3} /\left[(1-v) r^{2}\right]
$$

Substituting the condition $R=r=b / 2$ and a Poisson's ratio of 0.28 into equation [4] yields:

$$
\mathrm{F}_{\mathrm{c}}=1.2 \mathrm{~Gb}^{2} \mathrm{e}
$$

At the point of contact between the solute atom and the dislocation, the line tension $\mathrm{T}$ at the critical condition just prior to breakeway is given by ${ }^{8}$ :

$$
T_{c}=G b^{2}\left[\ln \left(r_{1} / r_{0}\right)-1\right] /[4 \pi(1-v)]
$$

where $r_{1}$ is the spacing between dislocations and $r_{0}$ is the size of the dislocation core (which is normally approximately five times the Burger's vector. In the solution strengthened alloys of interest, the materials are normally in their well annealed state with an average dislocation density on the order of $10^{8} \mathrm{~cm}^{2}$. This yields a dislocation 
spacing $\left(r_{1}\right)$ of $10^{-4} \mathrm{~cm}$. Substituting $r_{1}=10^{-4} \mathrm{~cm}, r_{0}=5 b=1.2 \times 10^{-7} \mathrm{~cm}$ and $v=0.28$ into equation [7], the critical line tension for dislocation breakaway is:

$$
T_{c}=0.5 G b^{2}
$$

At this critical point, the parameters $\left(F_{c}, T_{c}\right.$ and $\left.\phi_{c}\right)$ in equation [1] will take on their respective critical values:

$$
2 \mathrm{~T}_{\mathrm{c}} \cos \left(\phi_{\mathrm{c}} / 2\right)=\mathrm{F}_{\mathrm{c}}
$$

From this equality, the critical bowing angle $\phi_{c}$ can be obtained. Combining equations [5], [7] and [8], the critical bowing angle for tungsten strengthened with three types of solutes (Re, $\mathrm{Nb}$ and $\mathrm{Hf})$ can be calculated. The parameter that distinguishes between the three alloys is the misfit coefficient e. The $\left(\phi_{c} / 2\right)$ values for $\mathrm{W}-\mathrm{Re}, \mathrm{W}-\mathrm{Nb}$ and $\mathrm{W}-$ $\mathrm{Hf}$ alloys are $89.0^{\circ}, 88.6^{\circ}$ and $85.8^{\circ}$ respectively. These angles are related to the maximum bowing of the dislocations prior to breakaway. It is evident that the critical bowing angle is not a strong function of the mismatch strain due to the presence of the solute.

The retardation of creep due to solution strengthening arises from the extra line length of the dislocation (due to bowing) that must be generated prior to the breakaway of the dislocation from the solute atoms. For a section of dislocation between two solute atoms separated by a distance $\mathrm{L}$, the increase in energy $\Delta \mathrm{E}$ to create this extra line length can be written as:

$$
\Delta \mathrm{E}=\mathrm{T}_{\mathrm{c}}(l-\mathrm{L}) / \mathrm{N}
$$

where $T_{c}$ is the critical line tension defined earlier, $l$ is the line length of the bow (larger than $\mathrm{L}$, the straight line distance) and $\mathrm{N}$ is the number of atoms within the volume that the bowing dislocation has swept through. The parameter $\mathbf{N}$ is related to the shaded area (S) in Figure 2 in the following manner:

$$
\mathrm{N}=\mathrm{Sb} /(2 \mathrm{R})^{3}
$$

The area $S$ (in Figure 2) can be calculated using simple geometry and is related to the other parameters of interest through:

$$
S=\left[\pi-\phi_{c}-\sin \phi_{c}\right] L^{2} /\left[8 \cos ^{2}\left(\phi_{c} / 2\right)\right]
$$

It is reasonable to assume that the solute atoms are distributed randomly in the matrix. 
The term $L$ is the average nearest neighbor distance between these atoms and is equal to $b / C^{1 / 2}$ where $C$ is the solute concentration. Substituting equations [10] and [11] into [9], the following expression for the extra energy required to free the dislocation from the pinning of the solute atoms:

$$
\Delta \mathrm{E}=(32 / 3) G R^{3} \mathrm{f}\left(\phi_{\mathrm{c}}\right)[(1+v) /(1-v)]\left(\mathrm{e} \mathrm{C}^{1 / 2}\right)
$$

where'

$$
f\left(\phi_{c}\right)=\left[\pi-\phi_{c}-2 \cos \left(\phi_{c} / 2\right)\right] /\left[\pi-\phi_{c}-\sin \phi_{c}\right]
$$

As discussed earlier, the value of $\phi_{c}$ is relatively insensitive to the selection of solute. This implies that the term $f\left(\phi_{c}\right)$ is also quite insensitive to materials. For the three alloying elements selected, the value of $f\left(\phi_{c}\right)$ is approximately 0.25 .

The extra energy needed to free a climbing dislocation from solute pinning sites (given in equation 12) can be used to calculate the reduction in creep due to the presence of such solute atoms. Since $\Delta \mathrm{E}$ can be treated as an extra activation energy for creep, it is feasible to account for this strengthening effect by introducing an additional rate limiting term of the form $\exp (-\Delta E / k T)$ to the creep for the pure material. The creep rate of a strengthened alloy $\left(\dot{\epsilon}_{\text {allog }}\right)$ is therefore related to the creep rate of the pure materials ( $\left.\dot{\epsilon}_{\text {pure }}\right)$ via the equation:

$$
\dot{\epsilon}_{\text {alloy }}=\dot{\epsilon}_{\text {pure }} \exp (-\Delta \mathrm{E} / \mathrm{kT})
$$

where

$$
\Delta E=1.2 \times 10^{-29}\left(\mathrm{~m}^{3}\right) \mathrm{GeC}^{1 / 2}
$$

Creep data are available for three tungsten based alloys (W-Re, W-Nb and W-Hf). The three solutes possess different size mismatch as shown in Table 1. At a temperature of $2200 \mathrm{~K}$, the exponential term $\Delta \mathrm{E} / \mathrm{kT}$ becomes $4.10 \times 10^{-10} \mathrm{GeC}^{1 / 2}$.

Based on the formulation developed above, the creep data available in the literature for different alloys were analyzed to verify the effects of atomic size misfit and concentration. An examination of the literature reveals that most creep test of these alloys were conducted to determine the stress required to create a $10^{-6} \mathrm{~s}^{-1} \mathrm{creep}$ rate at $2200 \mathrm{~K}$. The extent of these data is insufficient to fully characterize the creep behavior through an analysis using the conventional $\log \dot{\epsilon}$ versus $\log \sigma$ approach. 
Furthermore in W-Hf and W-5Re alloys, it was found that the log of the strain rate versus $\log$ of the stress lines are parallel to that obtained for pure tungsten, ${ }^{9}$, this implies that it is possible to account for the solute effects by a shift factor related to $\mathrm{eC}^{1 / 2}$. The general creep equation of alloy can be related to the creep of the same material but without solution strengthening as:

$$
\therefore \dot{\epsilon}_{\text {dloy }}=\dot{\epsilon}_{\text {puro }} \exp \left(-\mathrm{KeC}^{1 / 2}\right)
$$

Since the creep these materials in their pure state obeys the power law dependence on applied stress: $\dot{\epsilon}_{\text {pure }}=A \sigma^{a}$ where $n$ is the stress power exponent, equation [16] can be written as:

$$
\dot{\epsilon}_{\text {alloy }}=A \sigma^{\mathrm{a}} \exp \left(-\mathrm{KeC}^{1 / 2}\right)
$$

As mentioned earlier, much of the data in solution strengthened refractory single crystals is expressed in terms of the stress required to generate a constant creep rate of $10^{-6} \mathrm{~s}^{-1}$, taking $\log$ of equation [17] yields:

$$
-6=\log _{10} \mathrm{~A}+\operatorname{nlog}_{10} \sigma+\left(-\mathrm{KeC}^{1 / 2}\right) / \ln 10
$$

Again using $\dot{\epsilon}_{\text {pure }}=10^{-6} \mathrm{~s}^{-1}$ and $\dot{\epsilon}_{\text {pure }}=A \sigma_{\text {pure }}$, where $\sigma_{\text {pure }}$ is the creep strength of the pure metal at a similar strain rate of $10^{\text {pure }} \mathrm{s}^{-1}$, the following expression is obtained from equation [18]:

$$
\log _{10} \sigma_{\text {alloy }}=\left(\mathrm{KeC}^{1 / 2}\right) /(\operatorname{nln} 10)+\log _{10} \sigma_{\text {pure }}
$$

where $\sigma_{\text {alloy }}$ and $\sigma_{\text {pure }}$ are the stress required to produce a creep rate of $10^{-6} \mathrm{~s}^{-1}$ in the selected alloys and pure materials respectively. Figure 3 shows the experimental data obtained from three different solution strengthened tungsten alloys presented in a fashion in accordance with equation $18\left(\log \sigma\right.$ versus $\left.\mathrm{eC}^{1 / 2}\right)$. The slope of the line is related to the constant $\mathrm{K}$ whereas the $\mathrm{y}$-intercept is the stress observed in pure tungsten. The slope of this straight line is $28.66(=\mathrm{K} / \mathrm{n} \ln 10)$ giving a $\mathrm{K}$ value of 330 for $n=5$. The $y$-intercept obtained from the model is $7.4\left(=\log _{10} \sigma_{\text {pure }}\right)$ yield a $\sigma_{\text {pure }}$ value of $23 \mathrm{MPa}$. which is in accord with the experimental determined value of 24 $\mathrm{MPa}$. In addition, the parameter $\mathrm{K}$ is proportional to the dynamic shear modulus of the material $(G)$ as illustrated in equation 15 . The $K$ value of 330 obtained from data fitting corresponds to a dynamic shear modulus of $805 \mathrm{GPa}$, which is about six times higher than that observed in pure tungsten at $2200 \mathrm{~K}\left(\mathrm{G}_{\text {pure }}\right.$ is $\left.121 \mathrm{GPa}\right)$. This implies that the presence of solute atoms results in stronger elastic interaction with dislocation compared to the material in its pure state. 
$\because \quad$ The model developed is based on the simple strain interaction between dislocations and solute atoms. The ability of this model to fit the available data strengthens the confidence of our assumption that the creep resistance of the solid solution alloy comes from the extra activation energy required for creep in tungsten alloys. Equation 19 can be used to serve as a guidance for further improvement of the above creep model and for new alloy development.

\section{References:}

[1] N.G. Tachkova et al, Russian Metallurgy, No.1, (1987) 153.

[2] A. Gindin et al, Fiz. Metal. Metalloved. 28, No. 6, (1969) 1046.

[3] A. Clauer et al, Acta Met. 18, (1970) 367.

[4] V.A. Kononenko et al., Fiz Metal. Metalloved., No. 4, (1991) 181.

[5] Yu. S. Belomyttsev et al., Russian Metallurgy, No. 1, (1984) 90.

[6] A.H. Cottrell and B.A. Bilby, Proc. Roy. Soc., A62, 49(1949).

[7] F. Laves, Crystal Structure and Atomic Size. Theory of Alloy Phases, ASM, 1956, p. 124.

[8] J. Friedel, Dislocations, Pergamon Press, 1964, p.22.

[9] P.L. Raffo and W.D. Klopp, Mechanical Properties of Solid Solution and Carbide-Strengthened Arc-Melted Tungsten Alloys, NASA TN D-3248, Lewis Reseaech Center, Cleveland, Ohio, (1966).

[10] R.R. Vandervoot, The Creep Behavior of W-5Re, Metall Trans. 1(1970) pp.857-864. 


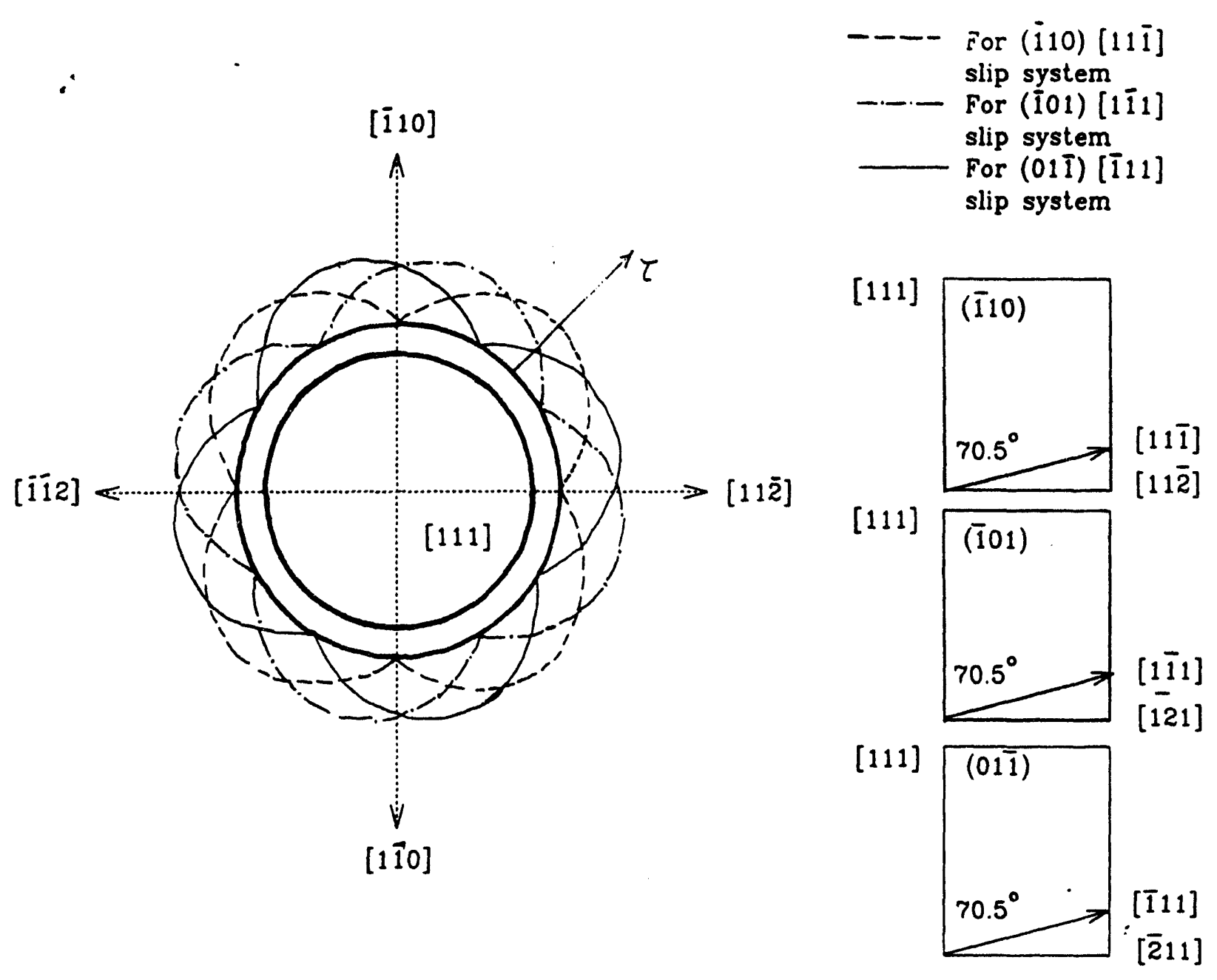

Figure 1. Resolved shear stress distribution in a body-centered cubic structure single crystalline tube grown in the [111] direction. 

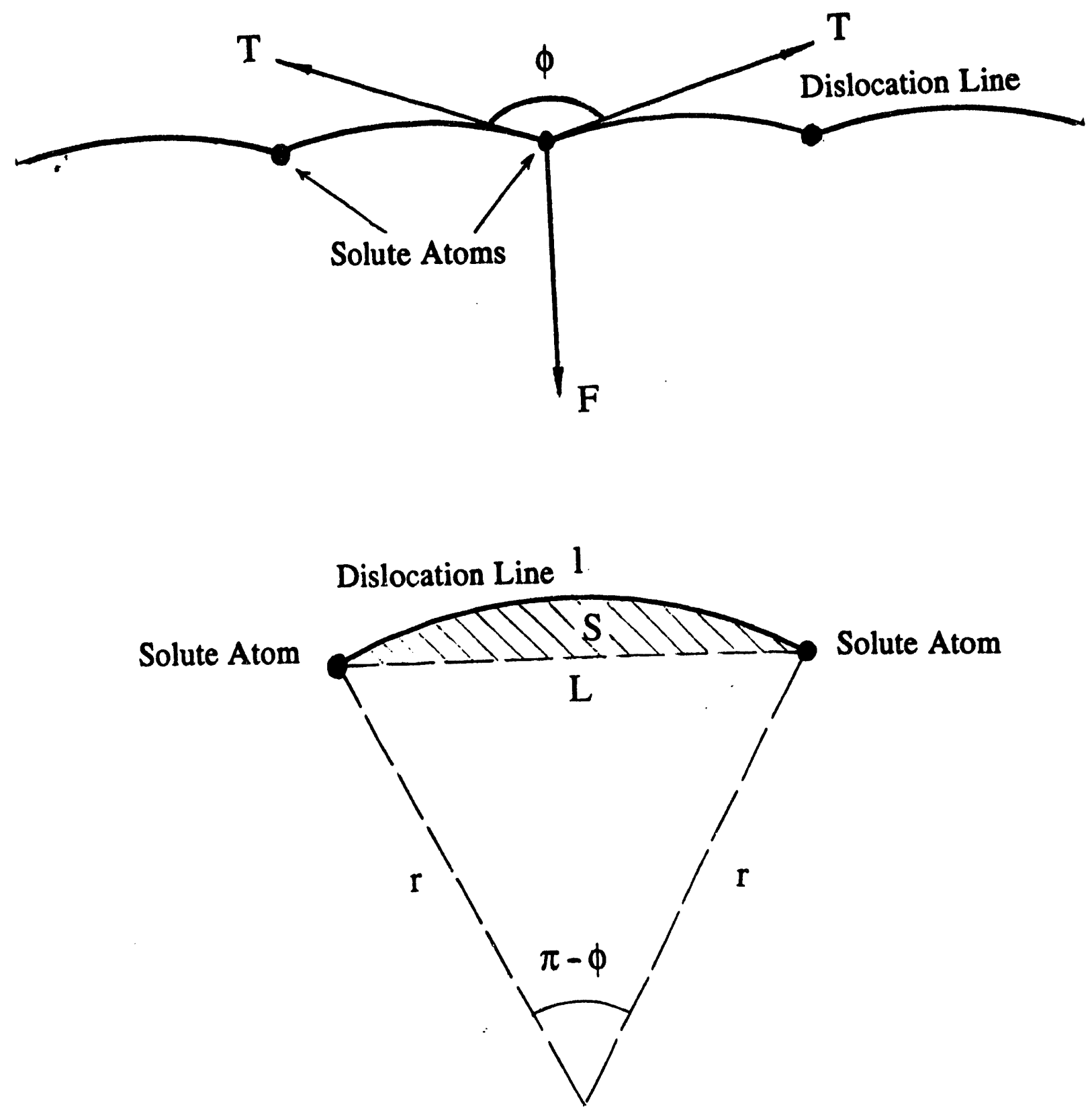

Figure 2. Schematic drawing showing the interaction of a climbing dislocation with solute atoms resulting in creep reduction. 


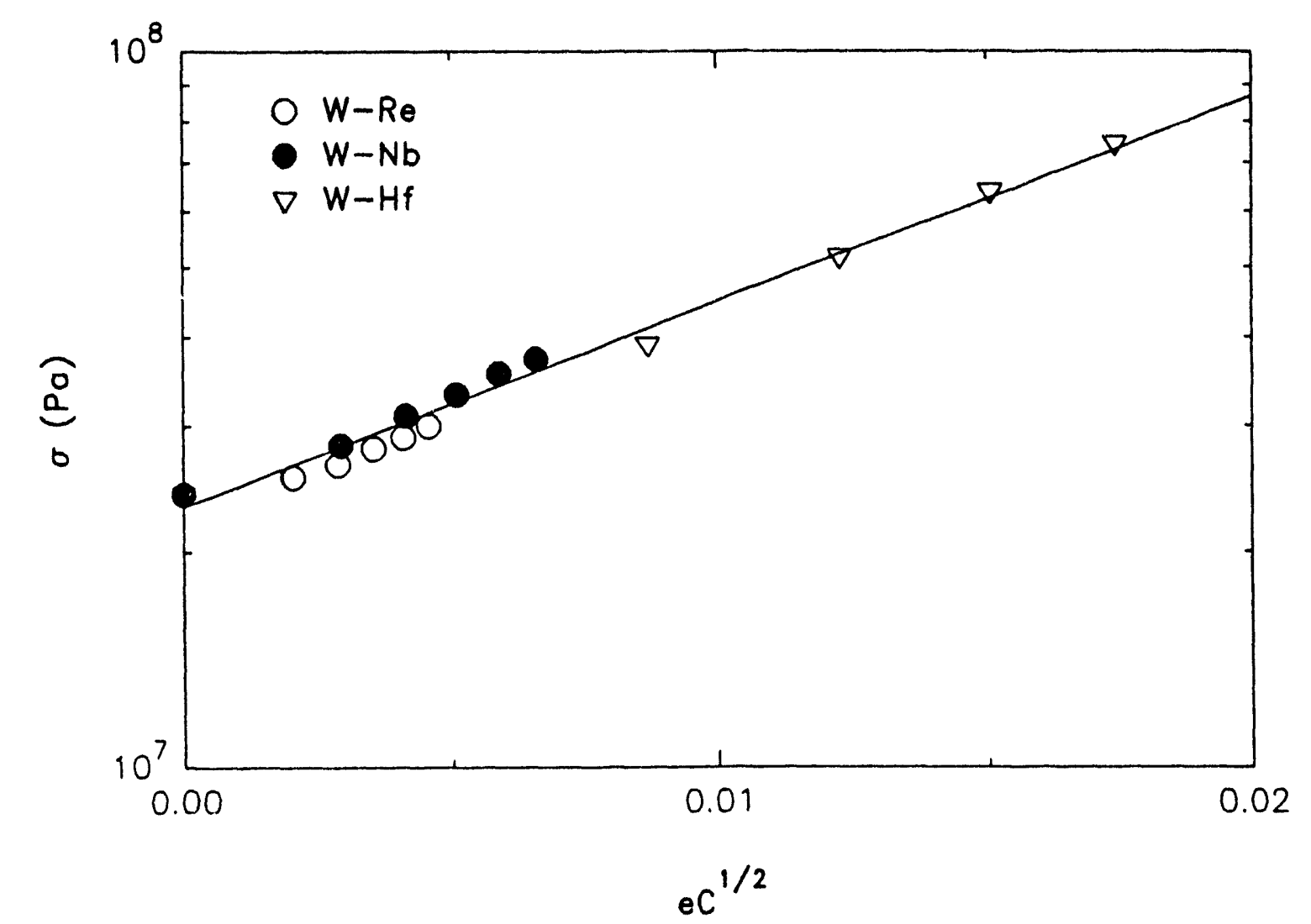

Figure 3. Master curve showing the stress required to produce a creep rate of $10^{-6} \mathrm{~s}^{-1}$ at $2200 \mathrm{~K}$ in three tungsten alloys as a function of concentration and size misfit of the solute atoms selected. The linearity of the master curve is indicative of the accuracy of the proposed model. 

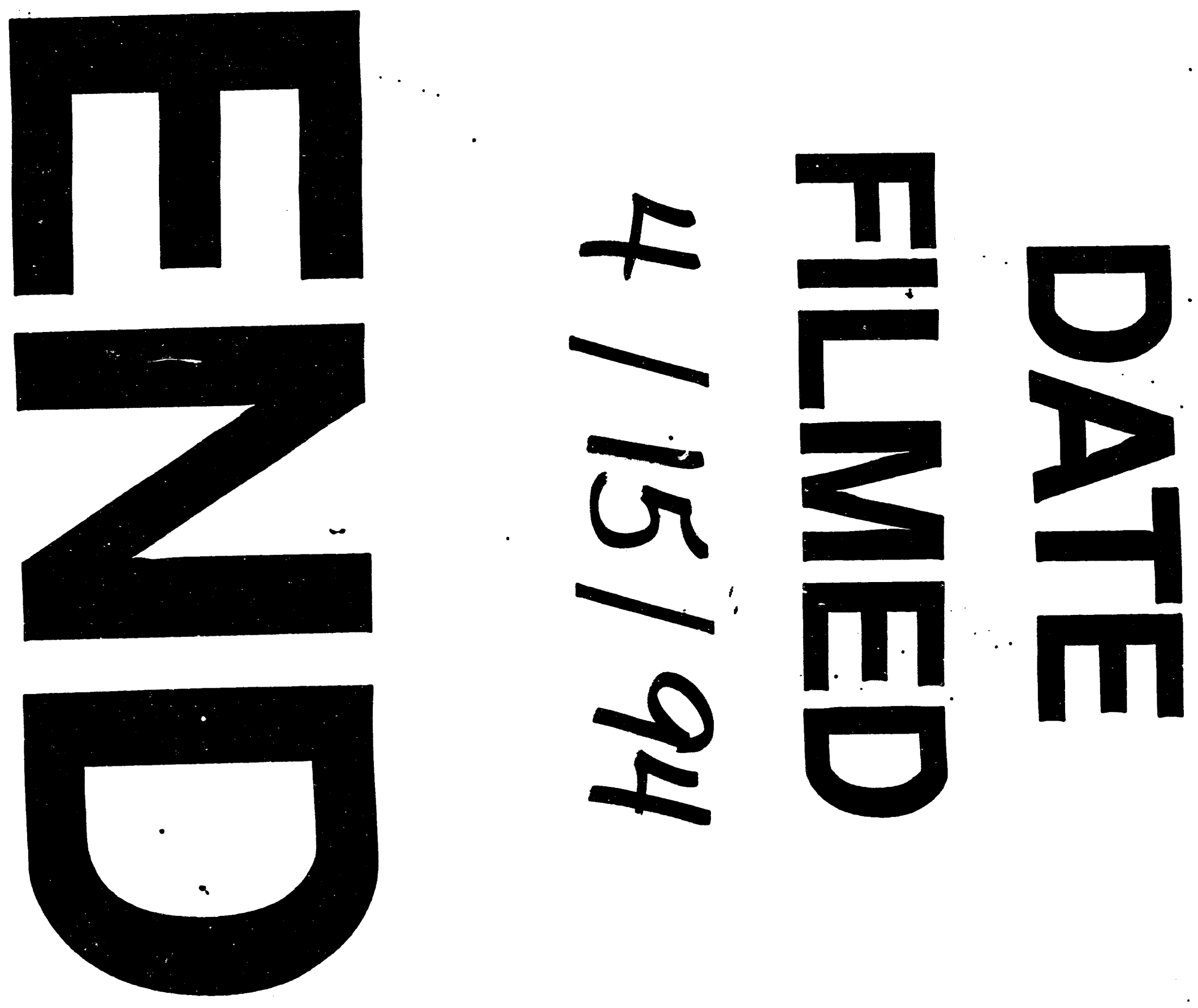
